\title{
CB2 Receptor Activation Ameliorates the Proinflammatory Activity in Acute Lung Injury Induced by Paraquat
}

\author{
Zhenning Liu, Yu Wang, Hongyu Zhao, Qiang Zheng, Li Xiao, and Min Zhao \\ Department of Emergency Medicine, Shengjing Hospital of China Medical University, No. 36 Sanhao Street, Heping District, \\ Shenyang, Liaoning 110004, China
}

Correspondence should be addressed to Min Zhao; wfzd999@126.com

Received 8 March 2014; Accepted 8 May 2014; Published 22 May 2014

Academic Editor: Stephen C. Land

Copyright (C) 2014 Zhenning Liu et al. This is an open access article distributed under the Creative Commons Attribution License, which permits unrestricted use, distribution, and reproduction in any medium, provided the original work is properly cited.

Paraquat, a widely used herbicide, is well known to exhibit oxidative stress and lung injury. In the present study, we investigated the possible underlying mechanisms of cannabinoid receptor-2 (CB2) activation to ameliorate the proinflammatory activity induced by PQ in rats. JWH133, a CB2 agonist, was administered by intraperitoneal injection $1 \mathrm{~h}$ prior to PQ exposure. After PQ exposure for 4, 8,24 , and $72 \mathrm{~h}$, the bronchoalveolar lavage fluid was collected to determine levels of TNF- $\alpha$ and IL- $1 \beta$, and the arterial blood samples were collected for detection of $\mathrm{PaO}_{2}$ level. At $72 \mathrm{~h}$ after PQ exposure, lung tissues were collected to determine the lung wet-to-dry weight ratios, myeloperoxidase activity, lung histopathology, the protein expression level of CB2, MAPKs (ERK1/2, p38MAPK, and JNK1/2), and NF- $\kappa$ Bp65. After rats were pretreated with JWH133, PQ-induced lung edema and lung histopathological changes were significantly attenuated. PQ-induced TNF- $\alpha$ and IL- $1 \beta$ secretion in BALF, increases of $\mathrm{PaO}_{2}$ in arterial blood, and MPO levels in the lung tissue were significantly reduced. JWH133 could efficiently activate CB2, while inhibiting MAPKs and NF- $\kappa$ B activation. The results suggested that activating CB2 receptor exerted protective activity against PQ-induced ALI, and it potentially contributed to the suppression of the activation of MAPKs and NF- $\kappa$ B pathways.

\section{Introduction}

Paraquat $(\mathrm{PQ})$ poisoning is by far one of the most clinically significant herbicides in terms of morbidity and mortality. The main target organ for acute PQ toxicity is the lung as a consequence of its accumulation against a concentration gradient, through the highly developed polyamine uptake system, and due to its capacity to generate huge amounts of prooxidant reactive species through a strenuous redoxcycle pathway [1]. Besides, another cytotoxic effect of PQ is the outbreak of progressive inflammation evoked by reactive oxygen species (ROS). During the inflammatory response in lung, immune cells including macrophages, neutrophils, and lymphocytes become activated, releasing IL-1 $\beta$, TNF$\alpha$, and so on. It is pathologically characterized by lung edema, hemorrhage, interstitial inflammation, and bronchial epithelial cell proliferation [2]. Respiratory failure as a result of lung injury is the most common cause of death from PQ. Since the oxidative damage and the consequent inflammatory response are the major contributors to the toxic effects of
$P Q$, finding an effective and feasible option for preventing or treating the consequent damage becomes an urgent problem.

The endogenous cannabinoid system is composed of the cannabinoid receptor types 1 and 2 (CB1 and CB2), the endogenous ligands (endocannabinoids), and enzymes that synthesize and degrade endocannabinoids. CB2 is mainly expressed in immune cells including neutrophils, eosinophils, monocytes, and natural killer cells [3-6]. Activation of the cannabinoid-2 (CB2) receptors by endocannabinoids [7], or selective synthetic agonists, has been shown to protect against tissue damage in various experimental models of ischemic-reperfusion injury $[8,9]$, atherosclerosis/cardiovascular inflammation [10], and other disorders by limiting inflammatory cell chemotaxis/infiltration, activation, and interrelated oxidative/nitrosative stress [11-14]. However, there are no reports that activating CB2 receptor may exert protective effects on PQ-induced acute lung injury and its potential biological mechanisms at present. In the present study, we investigated whether activating CB2 receptor has protective effects on PQ-induced acute lung injury in 
a rat model. In particular, we sought to further explore the role of the $\mathrm{CB} 2$ receptor in the process and investigate its underlying mechanisms.

\section{Materials and Methods}

2.1. Animals. Male Sprague-Dawley rats weighing 200-250 g were purchased from the Experimental Animal Center of China Medical University. Rats were housed in cages in a temperature-controlled $\left(20-25^{\circ} \mathrm{C}\right)$ and humidity-controlled (40-70\%) environment with a daily light-dark cycle. The rats had access to food and water ad libitum. All animal experiments were conducted in accordance with the Institutional Animal Ethics Committee and Animal Care Guidelines of China Medical University governing the use of experimental animals.

2.2. Reagents. PQ was purchased from Sigma-Aldrich (St. Louis, MO, USA). CB2R-agonist JWH133 was obtained from Enzo Life Sciences Ltd. (UK). Antibodies to p38MAPK, phosphor-p38MAPK, JNK1/2, phosphor-JNK1/2, ERK1/2, phosphor-ERK1/2, NF- $\kappa$ Bp 65 , I $\kappa$ B- $\alpha$, phosphor-I $\kappa \mathrm{B} \alpha$, and $\beta$ actin were purchased from Cell Signaling Technology Inc. (Beverly, MA, USA). Rabbit anti-CB2 receptor polyclonal antibody was purchased from Santa Cruz Biotechnology Inc. (Santa Cruz, CA). The rat MPO determination kit was purchased from Jiancheng Bioengineering Institute of Nanjing (Nanjing, China). The ELISA kits for TNF- $\alpha$ and IL- $1 \beta$ were purchased from R\&D system (R\&D, USA).

2.3. Experimental Protocols. After adapting to the environment, the rats were randomly distributed into four groups: control group ( $1 \mathrm{~mL}$ normal saline solution, i.p. $n=24)$, PQ group $(n=24)$, low dose JWH133 $(5 \mathrm{mg} / \mathrm{kg}$, i.p. $)+$ PQ group $(n=24)$, and high dose JWH133 (20 mg/kg, i.p.) + PQ group $(n=24)$. JWH133 was intraperitoneally administered at doses of 5 and $20 \mathrm{mg} / \mathrm{kg}$. After $1 \mathrm{~h}, \mathrm{PQ}$ was intraperitoneally administered at a dose of $20 \mathrm{mg} / \mathrm{kg}$ according to our previous research [15]. At 4, 8, 24, and $72 \mathrm{~h}$ after PQ administration, 6 rats were taken from each group at each endpoint for testing. Throughout the study period, each rat was observed carefully for clinical signs of PQ-related toxicity.

2.4. $\mathrm{PaO}_{2}$ Analysis in Arterial Blood. Arterial blood samples collected from the carotid arteries of the rats at 4, 8, 24, and $72 \mathrm{~h}$ after PQ administration were analyzed using a standard blood gas analyzer (ABL 505; Radiometer, Copenhagen, Denmark).

2.5. Wet-to-Dry (W/D) Lung Weight Ratios. The rats were killed via exsanguination $72 \mathrm{~h}$ after PQ administration. The whole lungs were removed. Each lung was dried, weighed, and then placed in an oven at $80^{\circ} \mathrm{C}$ for $48 \mathrm{~h}$ to obtain the "dry" weight. The ratio of the weight of the wet lung to the weight of the dry lung was calculated to assess tissue edema [16].

2.6. Histopathologic Evaluations. The rats were killed $72 \mathrm{~h}$ after PQ administration. The lungs were then removed and stored in $4 \%$ paraformaldehyde for $48 \mathrm{~h}$ at $4^{\circ} \mathrm{C}$. Hematoxylin and eosin staining was carried out according to the regular staining method, and the slides were evaluated using a semiquantitative scoring method. Lung injury was graded in a blinded fashion from 0 (normal) to 4 (severe) for interstitial inflammation, neutrophil infiltration, congestion, and edema. The total lung injury score was calculated by adding up the individual scores from each category [16].

2.7. BALF Collection. At 4, 8, 24, and $72 \mathrm{~h}$ after PQ administration, rats were euthanized and BALF was performed on the left lung with $4 \mathrm{~mL}$ phosphate-balanced saline solution in $2.5 \mathrm{~mL}$ aliquots after cannulation of the left trachea. The collected BALF was centrifuged at $1000 \mathrm{~g}$ for $10 \mathrm{~min}$; the supernatant was collected and stored at $-80^{\circ} \mathrm{C}$, for later TNF$\alpha$ and IL- $1 \beta$ levels measurement.

2.8. TNF- $\alpha$ and IL-1 $\beta$ ELISA Assays. The levels of TNF- $\alpha$ and IL- $1 \beta$ in the BALF were measured via ELISA assays using commercially available kits according to the manufacturer's recommended instructions. The levels of TNF- $\alpha$ and IL- $1 \beta$ in the samples were calculated based on a standard curve. The detection ranges of the TNF- $\alpha$ and IL- $1 \beta$ ELISA assays were $12.5-800 \mathrm{pg} / \mathrm{mL}$ and $31.25-2000 \mathrm{pg} / \mathrm{mL}$, respectively. Samples that had a concentration that exceeded the limit of the standard curve were measured after dilution.

2.9. Pulmonary MPO Activity. The activity of MPO was determined in the lung tissue by MPO kit (Nanjing Jiancheng, China). At 4, 8, 24, and $72 \mathrm{~h}$ after PQ treatment, rats were killed and the left lungs were excised. One hundred milligrams of lung tissue was homogenized and fluidized in extraction buffer to obtain $5 \%$ of the homogenate. The sample including $0.9 \mathrm{~mL}$ homogenate and $0.1 \mathrm{~mL}$ of reaction buffer was heated to $37^{\circ} \mathrm{C}$ in a water bath for $15 \mathrm{~min}$, and then the enzymatic activity was determined by measuring the changes in absorbance at $460 \mathrm{~nm}$ using a 96-well plate reader and expressed as $\mathrm{U} / \mathrm{g}$ weight.

2.10. Immunohistochemistry. The lung tissues were fixed in $4 \%$ paraformaldehyde for $48 \mathrm{~h}$ at $4^{\circ} \mathrm{C}$ and processed for paraffin embedding. Paraffin-embedded blocks were cut into $4 \mu \mathrm{m}$ thick sections and mounted onto slides. The sections were pretreated at $60^{\circ} \mathrm{C}$ for $1 \mathrm{~h}$, then dewaxed in xylene, hydrated, and washed in $0.01 \mathrm{~mol} / \mathrm{L}$ of citrate buffer. After inhibiting endogenous peroxidase using 3\% $\mathrm{H}_{2} \mathrm{O}_{2}$ in methanol, the sections were incubated with antiCB2R polyclonal antibody overnight at $4^{\circ} \mathrm{C}$. The sections were then thoroughly washed with a phosphate-buffered saline (PBS) solution, after which point the corresponding secondary antibodies were applied and incubated at room temperature for $30 \mathrm{~min}$. Reaction products were visualized following incubation with diaminobenzidine (DAB) and then counterstained with hematoxylin. Negative controls were generated by omitting the primary antibodies.

2.11. Western Blot Analysis. Lung tissue samples were harvested and frozen in liquid nitrogen immediately until 
homogenization. Proteins were extracted from the lungs using a Nuclear and Cytoplasmic Protein Extraction Kit (Beyotime Biotechnology, China) according to the manufacturer's protocol. To extract the total protein from lung tissue, protein concentrations were determined by BCA protein assay kit and equal amounts of protein were loaded per well on a $10 \%$ sodium dodecyl sulphate polyacrylamide gel (SDS-PAGE). Subsequently, proteins were transferred onto polyvinylidene difluoride membrane. The membranes were washed in Tris-buffered saline with Tween 20 and incubated in $5 \%$ skim milk (Sigma) at room temperature for $2 \mathrm{~h}$ on a rotary shaker and followed by TBS-T washing. Incubations with rabbit polyclonal antibodies specific for CB2 receptor, p38MAPK, phosphor-p38MAPK, JNK1/2, phosphor-JNK1/2, ERK1/2, phosphor-ERK1/2, NF- $\kappa$ Bp 65 , I $\kappa$ B- $\alpha$, and phosphor$\mathrm{I} \kappa \mathrm{B} \alpha$ in diluent buffer (5\% skim milk in TBST) were performed overnight at $4^{\circ} \mathrm{C}$. Then the membrane was washed with TBS-T followed by incubation with the peroxidaseconjugated secondary antibody at room temperature for $1 \mathrm{~h}$. Immunoreactive bands were visualized with an enhanced chemiluminescence western blot kit in accordance with the manufacturer's instructions. The $\beta$-actin western blot was performed as the internal control of protein loading. The signals were detected with an enhanced chemiluminescence kit (Pierce) and exposed on X-ray film. After the film was scanned with a GS-700 imaging densitometer (Bio-Rad, Hercules, CA), a quantitative analysis was performed using Multi-Analyst software (Bio-Rad).

2.12. Statistical Analyses. The data are expressed as the means \pm SD. Statistical analyses were carried out using SPSS 16.0. One-way ANOVA followed by the Student-NewmanKeuls test was used to compare the results that were obtained in the different treatment groups. Differences were considered to be statistically significant when $P<0.05$.

\section{Results}

3.1. CB2 Activation Attenuates Lung W/D Ratios in Rats with PQ-Induced Acute Lung Injury. The lung W/D ratio was determined in order to assess the severity of pulmonary edema. As shown in Figures 1(a) and 1(b), the lung W/D ratios in the PQ-treated group were significantly higher than those in the control group at $72 \mathrm{~h}$ after $\mathrm{PQ}$ administration $(P<0.05)$. CB2 activation decreased the lung W/D ratios in rats with $\mathrm{PQ}$-induced lung injury $(P<0.05)$.

\subsection{CB2 Activation Improves PQ-Induced Histological Dam-} age. As shown in Figures 1(c) and 1(d), the lungs of rats which were exposed to PQ for $72 \mathrm{~h}$ displayed significant inflammatory alterations that were characterized by lung edema, alveolar hemorrhage, inflammatory cell infiltration, and destruction of alveolar structure. These effects were dramatically reduced and became more focal in JWH133treated rats, especially for high dose. The lung injury scores were significantly decreased dose-dependently.

3.3. CB2 Activation Attenuates Markers of Acute Lung Injury $\left(\mathrm{PaO}_{2}\right)$. For assessments of acute lung injury induced by
$\mathrm{PQ}, \mathrm{PaO}_{2}$, derived from the arterial blood samples, was measured individually. As shown in Figure 2(a), after $4 \mathrm{~h}$ of PQ poisoning, $\mathrm{PaO}_{2}$ decreased gradually compared to the control rats. $\mathrm{PaO}_{2}$ declined obviously for the $24 \mathrm{~h}$ and went down to the valley value. Compared to the PQ group, the decline extent of $\mathrm{PaO}_{2}$ was palliative in the JWH133-treated group.

3.4. CB2 Activation Attenuates PQ-Induced Marked Neutrophil Infiltration. Neutrophils were important mediators of the delayed tissue injury after PQ administration. An indicator of neutrophil infiltration was the MPO activity. In PQ poisoning group, the lung MPO activity was obviously elevated time-dependently compared to the control group. In contrast, the marked increase in lung MPO activity induced by PQ was largely attenuated by JWH133, especially for high dose JWH133 (Figure 2(b)).

3.5. CB2 Activation Attenuates PQ-Induced Proinflammatory Cytokine Secretion. The effects of JWH133 on the production of TNF- $\alpha$ and IL- $1 \beta$ in the BALF at $4,8,24$, and $72 \mathrm{~h}$ after PQ administration were analyzed with ELISA. As shown in Figures 2(c) and 2(d), treatment with PQ alone caused significant increases in TNF- $\alpha$ and IL- $1 \beta$ compared to the control group $(P<0.05)$. JWH133 markedly reduced the production of TNF- $\alpha$ and IL-1 $\beta$ at 24 or $72 \mathrm{~h}$ after PQ administration compared to the PQ-treated group $(P<$ 0.05). Compared to the L-JWH133 group, the effect was more significant in the H-JWH133 group.

3.6. CB2 Receptor Expression in the Lung Tissues of Rats with PQ-Induced Acute Lung Injury. CB2 receptor expression in the lung tissues was illustrated in Figure 3(a). In the control group, CB2 receptor positive signals were weakly observed in the lung tissues. At $72 \mathrm{~h}$ after PQ administration, CB2 receptor positive signals were further decreased in the lung tissues. Notably, JWH133 pretreatment significantly increased $\mathrm{CB} 2$ receptor positive signals in the lung tissues. The result of the western blotting analysis was illustrated in Figure 3(b). The PQ-treated group revealed decreased CB2 receptor expression as compared to the control group. JWH133 pretreatment significantly increased CB2 receptor expression in the lung tissues in a dose-dependent manner compared to the PQ-treated group $(P<0.05)$.

3.7. CB2 Activation Attenuates PQ-Induced p38MAPK, ERK1/2, and JNK1/2 Activation in Lung Tissue of Rats with $P Q$-Induced Acute Lung Injury. As shown in Figure 4, there was a marked increase in PQ-induced phosphorp38MAPK, phosphor-ERK1/2, and phosphor-JNK1/2 in the lung tissues. Pretreatment with JWH133 attenuated p38MAPK, ERK1/2, and JNK1/2 increases and inhibited the MAPKs phosphorylation compared to the PQ-treated group $(P<0.05)$. However, only p38MAPK phosphorylation was inhibited by JWH133 in a dose-dependent manner. the Lung Tissues of Rats with PQ-Induced Acute Lung Injury. 

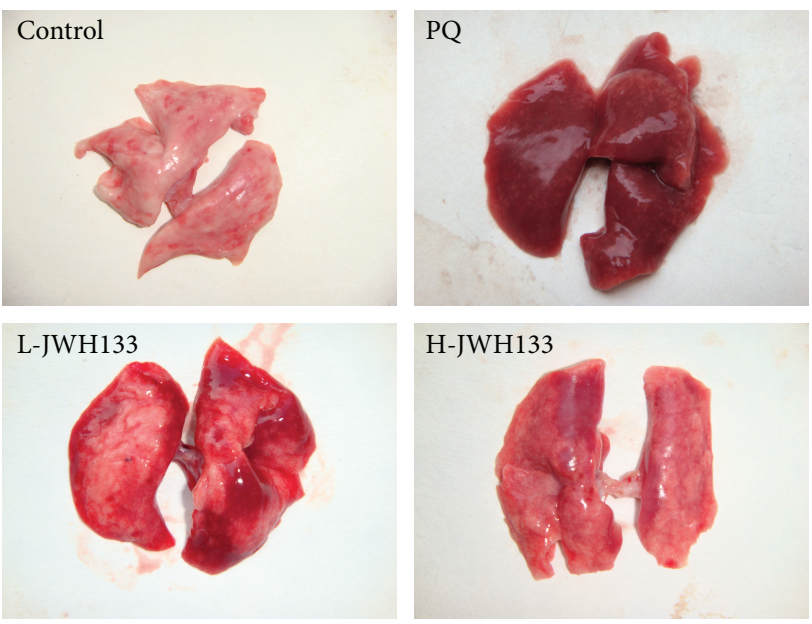

(a)
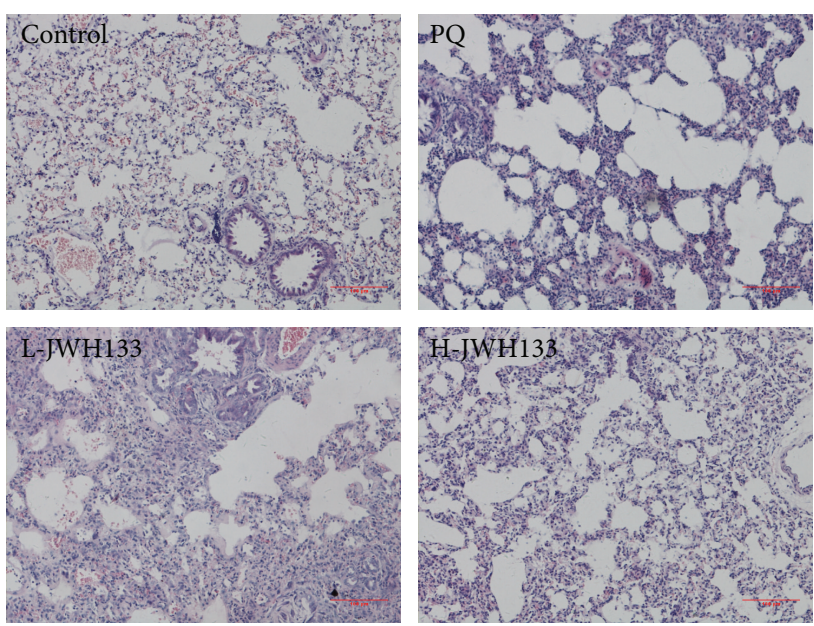

(c)

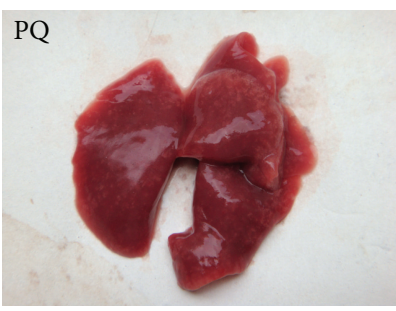

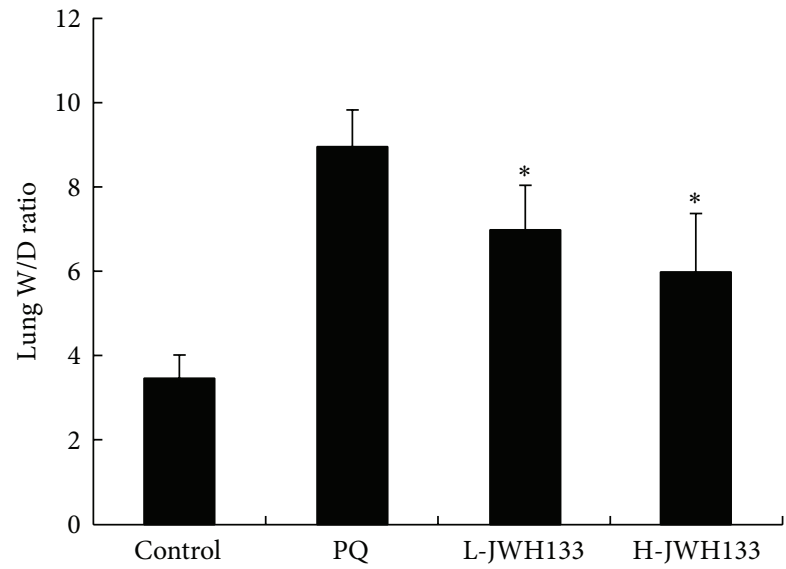

(b)

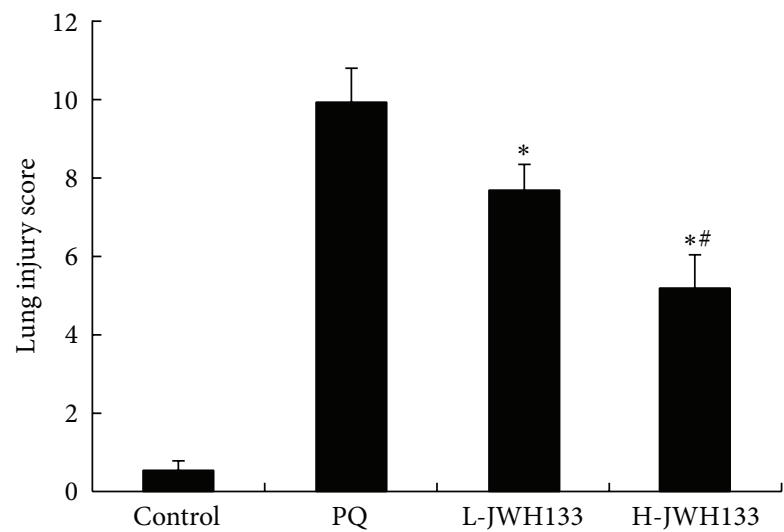

(d)

FIGURE 1: Effects of JWH133 on lung W/D ratio and histopathological changes in lung tissues of PQ-induced acute lung injury rats. JWH133 was intraperitoneally administered $1 \mathrm{~h}$ before intraperitoneal administration of PQ. The lung W/D ratio $(\mathrm{a}, \mathrm{b})$ and lung histological evaluation (c, d, HE staining) were determined after PQ administration for $72 \mathrm{~h}$. L-JWH133: JWH133 at the low dose of 5 mg/kg and H-JWH133: JWH133 at the high dose of $20 \mathrm{mg} / \mathrm{kg}$. The values presented are the mean $\pm \mathrm{SD} .{ }^{*} P<0.05$ versus $\mathrm{PQ}$ group; ${ }^{\#} P<0.05$ versus L-JWH133 group.

As shown in Figure 5(a), the PQ-treated group displayed significant increase in the levels of the p65 subunit of NF- $\kappa \mathrm{B}$ in the nuclear extracts. In contrast, JWH133 treatment significantly decreased the levels of the p65 subunit of NF- $\kappa$ B dosedependently $(P<0.05)$. As shown in Figure 5(b), the PQtreated group displayed significant $\mathrm{I} \kappa \mathrm{B}-\alpha$ degradation and phosphorylation compared to the control group. In contrast, $\mathrm{I} \kappa \mathrm{B}-\alpha$ degradation and phosphorylation in the JWH133pretreated groups were significantly reduced compared to the PQ-treated group $(P<0.05)$.

\section{Discussion}

Acute respiratory distress syndrome (ARDS) and acute lung injury (ALI) are the major causes of mortality and morbidity in $\mathrm{PQ}$ poisoning patients. Histologically, the acute exudative phase (the first 24-72 h) of ALI is characterized by infiltration of inflammatory cells and disruption of the alveolar-capillary barrier, leading to a proteinaceous exudate that floods the alveolar spaces and then impairs gas exchange and precipitates respiratory failure $[17,18]$. Arterial partial pressure of oxygen $\left(\mathrm{PaO}_{2}\right)$ and lung wet-to-dry weight $(\mathrm{W} / \mathrm{D})$ ratio can be used as indicators of lung injury according to previous reports $[19,20]$. To investigate the effects of JWH133 on PQinduced acute lung injury, we detected the lung W/D ratio of sampled lung tissues and $\mathrm{PaO}_{2}$ in arterial blood samples. The lung W/D ratio in the JWH133-pretreated group was significantly lower than that in the PQ-treated group. The $\mathrm{PaO}_{2}$ in arterial blood in the JWH133-pretreated group was higher than that in the PQ-treated group. Our experiments results suggested that treatment with JWH133 significantly attenuated lung edema and improved lung function. We also observed PQ-induced pathological alterations, including alveolar edema, hemorrhage, inflammatory cell infiltration, 


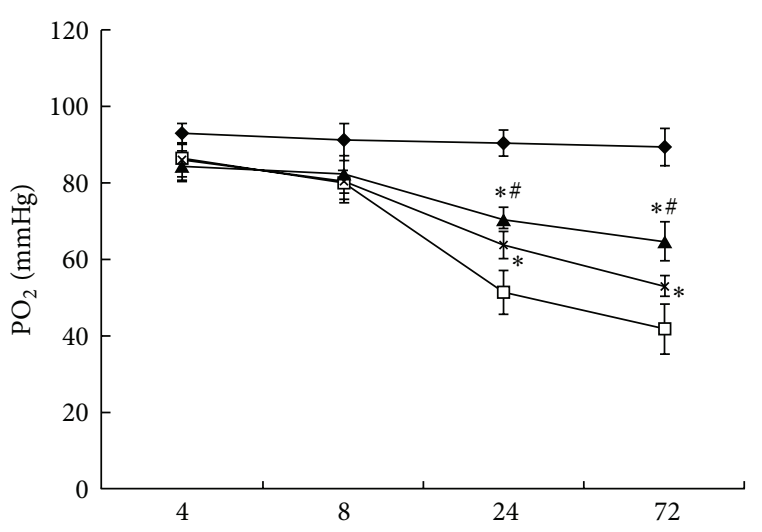

(h)

(a)

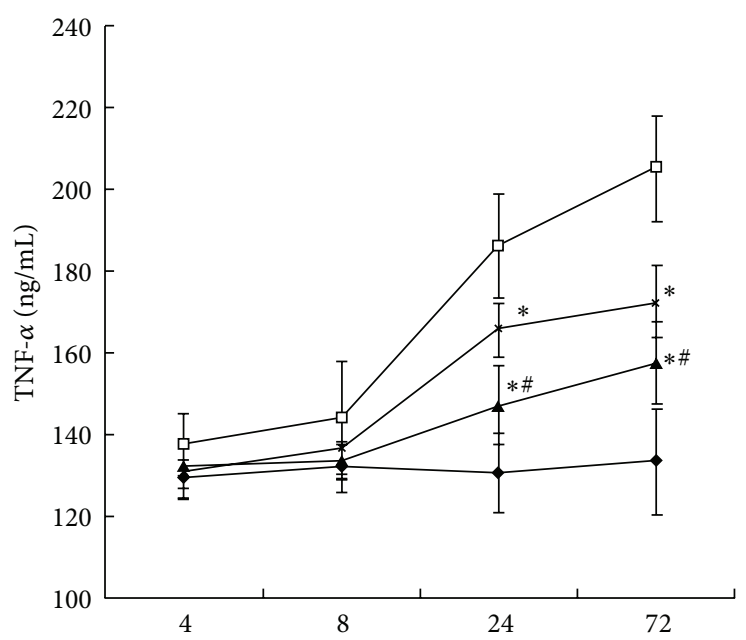

(h)

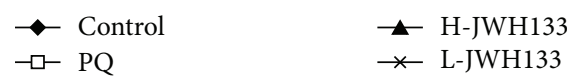

(c)

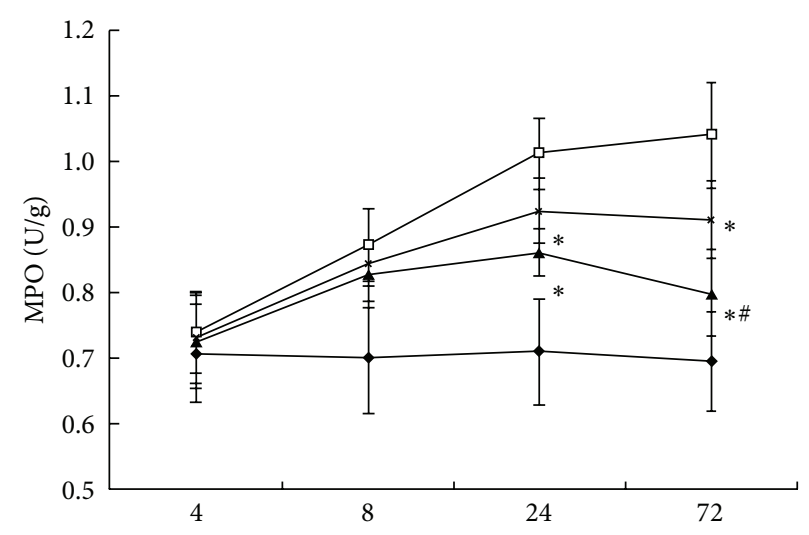

(h)

(b)

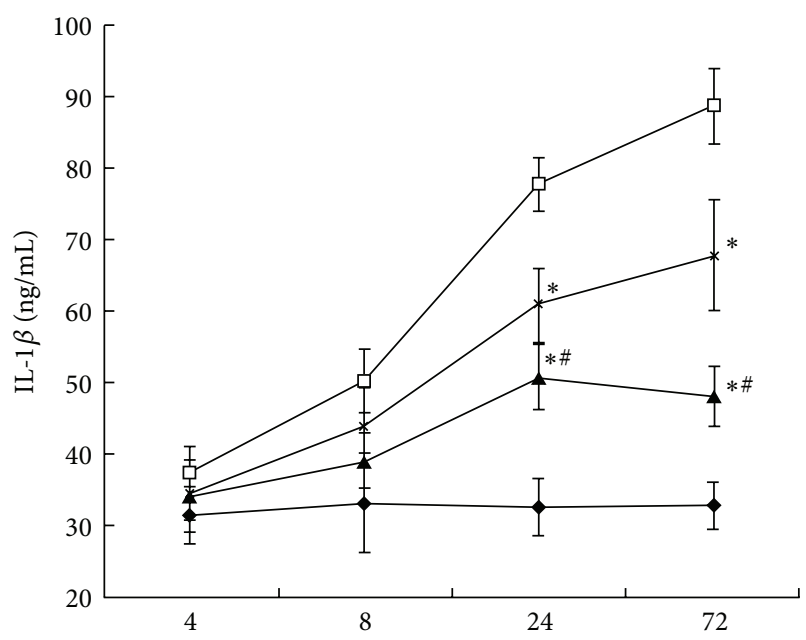

(h)

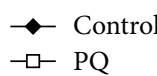

-JWH133 L-JWH133

(d)

FIGURE 2: Effects of JWH133 on the $\mathrm{PaO}_{2}$ in the arterial blood, MPO activity, and cytokine (IL-1 $\beta$ and TNF- $\alpha$ ) levels in the BALF of PQinduced acute lung injury rats. JWH133 was intraperitoneally administered $1 \mathrm{~h}$ before intraperitoneal administration of PQ. The arterial blood and BALF were collected after PQ administration for 4, 8, 24, and $72 \mathrm{~h}$ to analyze $\mathrm{PaO}_{2}$ level (a), MPO activity (b), and levels of TNF- $\alpha$ and IL-1 $\beta$ (c, d). L-JWH133: JWH133 at the low dose of $5 \mathrm{mg} / \mathrm{kg}$ and H-JWH133: JWH133 at the high dose of $20 \mathrm{mg} / \mathrm{kg}$. The values presented are the mean \pm SD. ${ }^{*} P<0.05$ versus $P Q$ group; ${ }^{\#} P<0.05$ versus L-JWH133 group.

and diffuse alveolar collapse that was accompanied by wall thickening. However, pretreatment with JWH133 was very effective at preventing PQ-induced lung tissue damage in rats. In ALI, the predominant inflammatory cells are the neutrophils, which play an important role in the development of most cases of ALI [21]. MPO is an enzyme located mainly in the primary granules of neutrophils and its main function is to kill microorganisms, but under certain conditions, it produces excess oxidant leading to tissue damage [22]. In our study, we found that the recruitment of neutrophils in the airways and MPO activity in the lungs were dramatically increased after PQ administration. In contrast, pretreatment of JWH133 significantly decreased MPO activity and reduced neutrophil infiltration.
Lung neutrophil recruitment and the subsequent lung injury are dependent upon the expression of the proinflammatory cytokines, such as TNF- $\alpha$ and IL-1 $\beta$ [23]. Both TNF$\alpha$ and IL- $1 \beta$ are the early cytokines that are released from alveolar macrophages in the early inflammatory phases of lung injury $[24,25]$. These cytokines, as well as other proinflammatory compounds, initiate, amplify, and perpetuate the inflammatory response during acute lung injury. TNF- $\alpha$ may play a role in the initiation or progression of multiple organ failure during endotoxic shock, and it has also been shown to be a particularly important mediator of acute lung injury [26]. IL- $1 \beta$ plays a key role in the development of acute lung injury and can inhibit fluid transport across the distal lung epithelium [27] causing surfactant abnormalities [28] and 

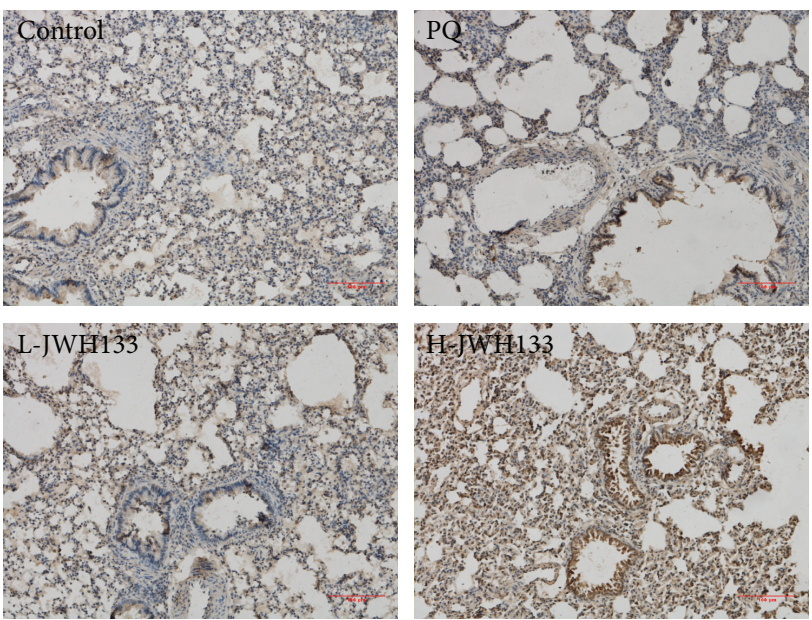

(a)

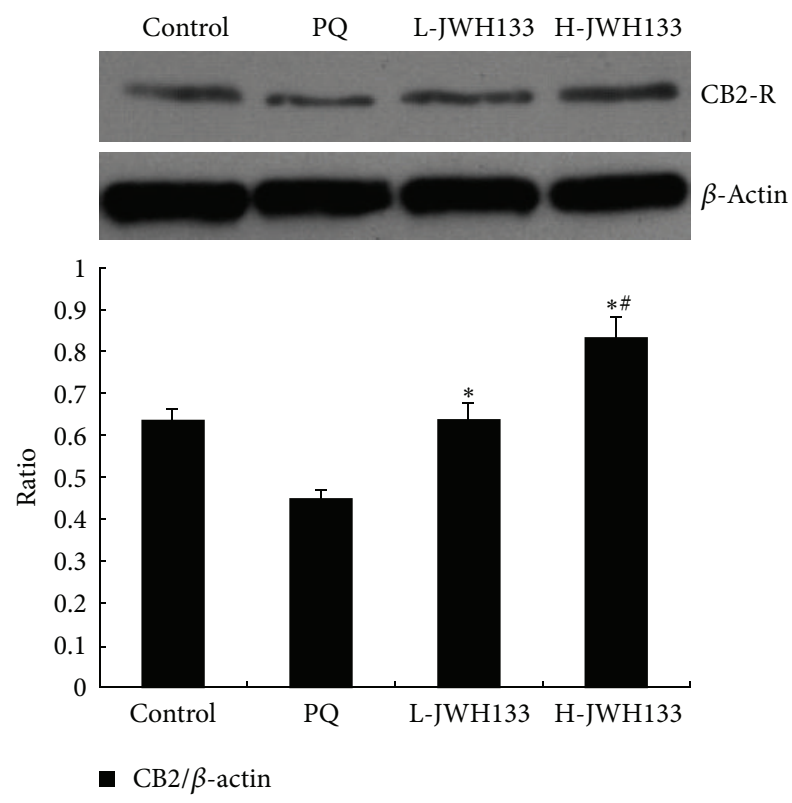

(b)

FIGURE 3: Effects of JWH133 on CB2 receptor in lung tissues of paraquat- (PQ-) induced acute lung injury rats. JWH133 was intraperitoneally administered $1 \mathrm{~h}$ before intraperitoneal administration of PQ. Lung tissue was collected after PQ administration for $72 \mathrm{~h}$ to determine the expression of CB2 receptor by immunohistochemistry (a) and Western blotting (b). L-JWH133: JWH133 at the low dose of $5 \mathrm{mg} / \mathrm{kg}$ and HJWH133: JWH133 at the high dose of $20 \mathrm{mg} / \mathrm{kg}$. The values presented are the mean $\pm \mathrm{SD} .{ }^{*} P<0.05$ versus $\mathrm{PQ}$ group; ${ }^{\#} P<0.05$ versus L-JWH133 group.

increasing protein permeability across the alveolar-capillary barrier [29]. In this experiment, we found that the levels of TNF- $\alpha$ and IL- $1 \beta$ were significantly increased in BALF of rats after PQ exposure. However, when the rats were pretreated with JWH133, the levels of TNF- $\alpha$ and IL- $1 \beta$ in BALF of PQpoisoned rats were significantly decreased. These findings indicate that CB2 activation effectively inhibited PQ-induced lung injury and inflammatory cells infiltration in vivo.

Pulmonary expression of these mediators, especially TNF- $\alpha$ and IL-1 $\beta$, has been linked to activation (nuclear translocation) of the transcription factor NF- $\kappa \mathrm{B}$ [30]. NF$\kappa \mathrm{B}$ is normally sequestered in the cytoplasm by a family of inhibitory proteins known as $\mathrm{I} \kappa \mathrm{Bs}$. A wide variety of stimuli, which have been extensively studied over the past two decades, can cause $\mathrm{I} \kappa \mathrm{B} \alpha$ phosphorylation, a process that is followed by its ubiquitination and subsequent degradation. The loss of $\mathrm{I} \kappa \mathrm{B} \alpha$ results in the release of the free NF$\kappa \mathrm{B}$ subunit $\mathrm{p} 65$, which translocates from the cytoplasm to the nucleus, where it triggers the transcription of multiple proinflammatory genes, including cytokines (TNF- $\alpha, \mathrm{IL}-1 \beta$, iNOS, COX2, etc.), chemokines, and adhesion molecules [31, 32 ]. Indeed, not only proinflammatory mediators (bacterial LPS, TNF- $\alpha$, IL- $1 \beta$, MMPs, COX2, and inducible nitric oxide synthase) $[33,34]$ but also ROS can activate intracellular transcription factors NF- $\kappa$ B. In our previous study [15], we demonstrated that PQ generate a great amount of ROS and activate NF- $\kappa$ B in rats. Meanwhile, it was also proved that NF$\kappa \mathrm{B}$ played an important role in lung injury in PQ-poisoned rats. Our results demonstrated that PQ induced $\mathrm{I} \kappa \mathrm{B}-\alpha$ degradation and phosphorylation, which increased the levels of the p65 subunit of NF- $\kappa \mathrm{B}$ in the nuclear extracts of lung tissues. In contrast, JWH133 treatment inhibited the degradation and phosphorylation of $\mathrm{I} \kappa \mathrm{B}-\alpha$ and decreased the levels of the p65 subunit of NF- $\kappa \mathrm{B}$ in the nuclear extracts of the lung tissues. Therefore, the potent anti-inflammatory effects of JWH133 may be suggested to involve I $\kappa \mathrm{B}-\alpha$ activation, which precipitates the translocation of the p 65 subunit from the cytoplasm to the nucleus. However, the cellular targets and molecular mechanisms that lead to JWH133-mediated $\mathrm{I} \kappa \mathrm{B}-\alpha$ activation remain to be elucidated.

MAPKs, which are a group of signaling molecules mainly consisting of three well-characterized subfamilies, involving ERK1/2, JNK1/2, and p38MAPK [35] are involved in signal transduction of extracellular hormones, growth factors, cytokines, and bacterial antigens and also play key roles in inflammatory reactions [36]. It has been found that p38 MAPK activation leads to increased expression of various cytokine genes including IL-1 $\beta$ [37], TNF- $\alpha$, IL- 8 , and IL$6[38,39]$. JNK1/2 and ERK1/2 inhibition has also shown efficacy in inhibiting the production of proinflammatory mediators [40]. Our results showed that MAPKs activities including ERK1/2, p38 MAPK, and JNK1/2 were all activated in the process of acute lung injury induced by PQ. However, pretreatment with JWH133 inhibited phosphorylation of ERK1/2, p38 MAPK, and JNK1/2, which suggested that JWH133 exerted the inhibitory effect on cytokine production by inhibiting the MAPKs activity. 

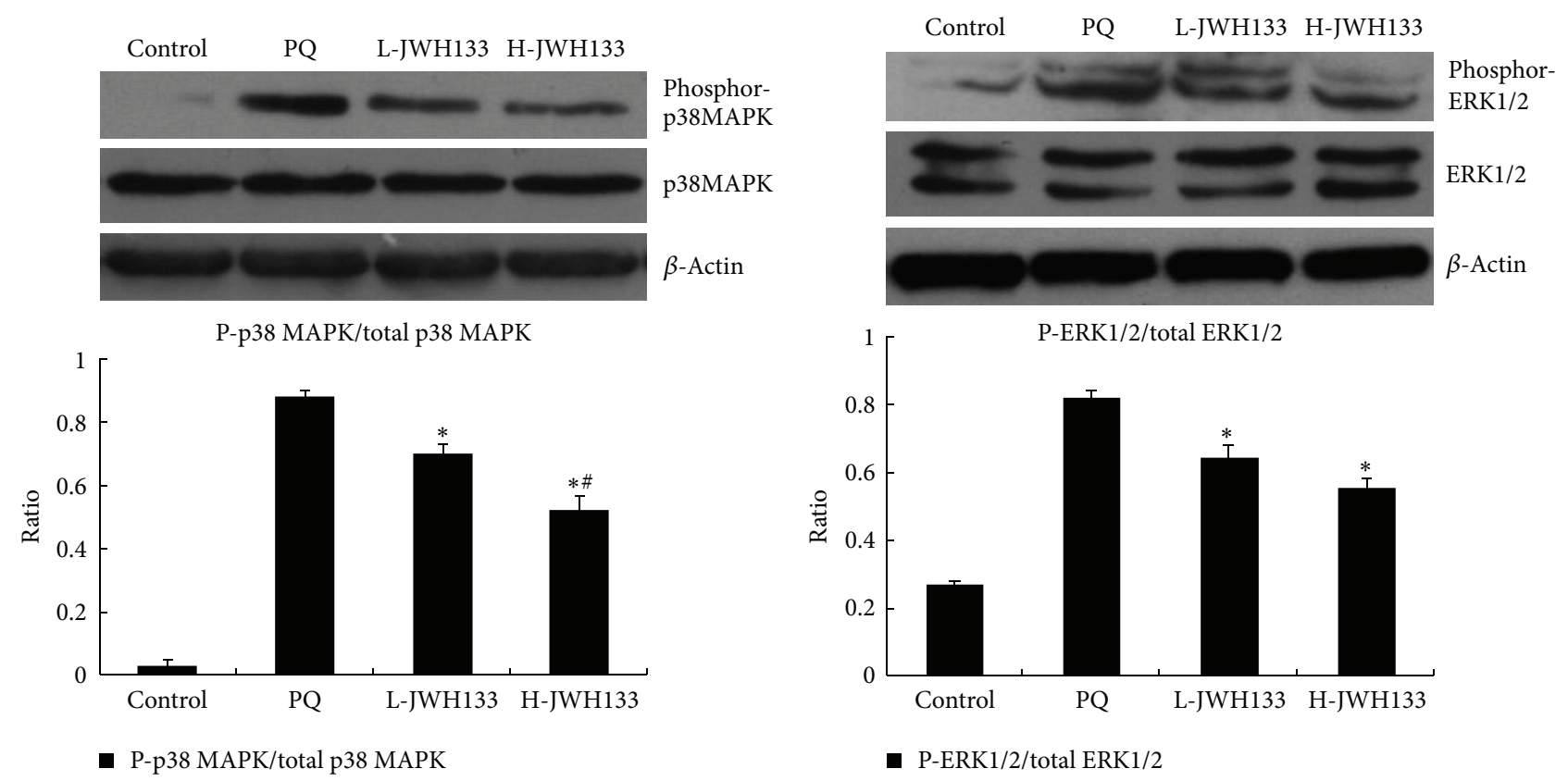

(a)

(b)

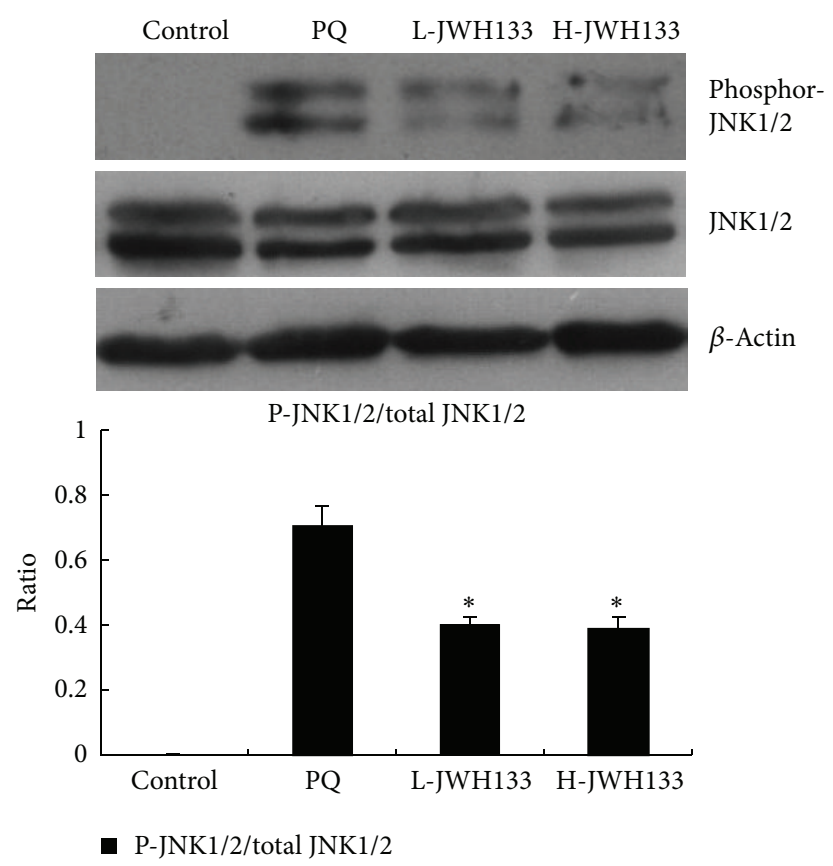

(c)

FIGURE 4: Effects of JWH133 on p38 MAPK, ERK1/2, and JNK1/2 signal transduction in lung tissues of PQ-induced acute lung injury rats. JWH133 was intraperitoneally administered $1 \mathrm{~h}$ before intraperitoneal administration of PQ. Lung tissue was collected after PQ administration for $72 \mathrm{~h}$ to determine the expression of $38 \mathrm{MAPK}, \mathrm{ERK} 1 / 2$, and JNK1/2 by Western blotting. L-JWH133: JWH133 at the low dose of $5 \mathrm{mg} / \mathrm{kg}$ and H-JWH133: JWH133 at the high dose of $20 \mathrm{mg} / \mathrm{kg}$. The values presented are the mean $\pm \mathrm{SD} .{ }^{*} P<0.05$ versus $\mathrm{PQ}$ group; ${ }^{\#} P<0.05$ versus L-JWH133 group.

Sustained ROS generation activated MAPKs (e.g., p38MAPK, ERK1/2, and JNK1/2) [41, 42] and proinflammatory pathways (e.g., NF- $\kappa$ B) $[43,44]$ in various cell types, in turn remodulating/regulating important inflammatory and cell survival and death processes in the previous studies such as placent [45] and hepatic I/R (ischaemia-reperfusion) [14]. The activation of MAPK/NF- $\kappa \mathrm{B}$ pathway plays a crucial role in many aspects of immune mediated inflammatory responses [46]. It has been found that MAPK pathway activation can lead to activation of the transcription 


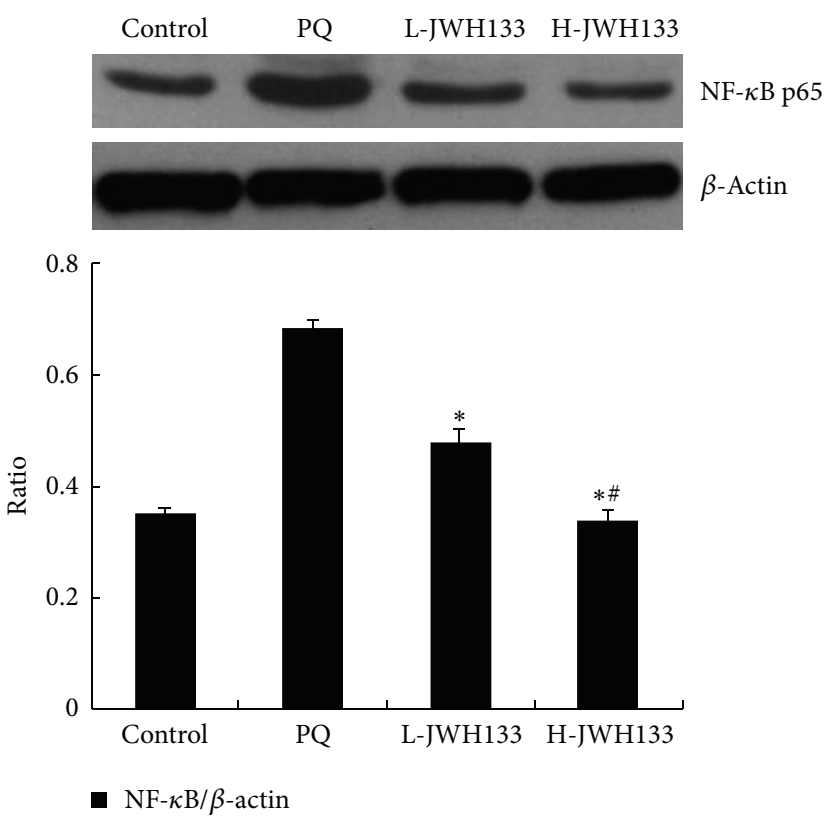

(a)

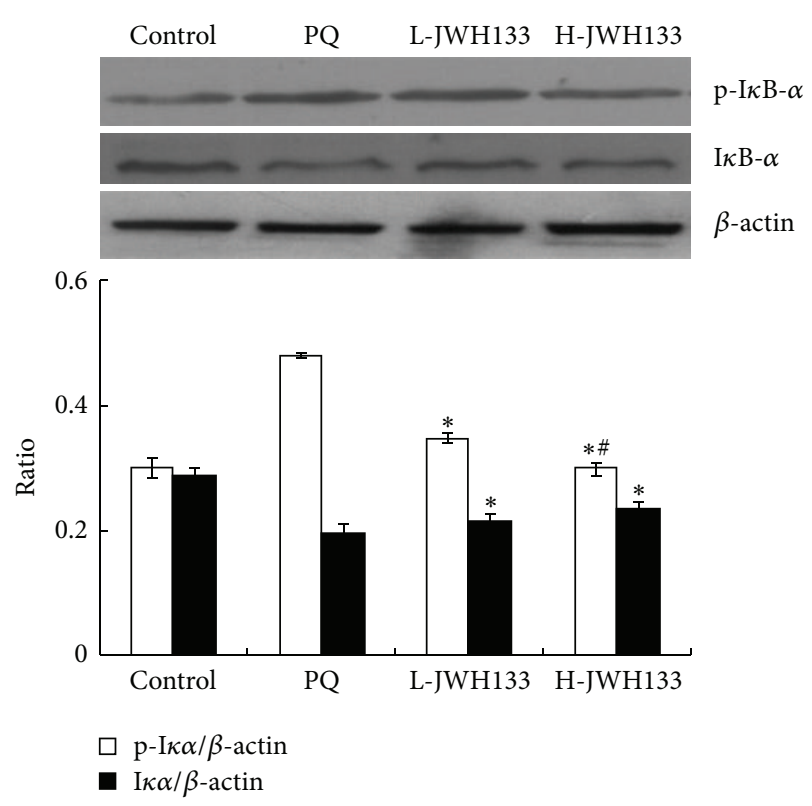

(b)

FIGURE 5: Effects of JWH133 on NF- $\kappa$ B signal transduction in lung tissues of PQ-induced acute lung injury rats. JWH133 was intraperitoneally administered $1 \mathrm{~h}$ before intraperitoneal administration of PQ. Lung tissue was collected after PQ administration for $72 \mathrm{~h}$ to determine the expression of NF- $\kappa$ B p65, I $\kappa$ B- $\alpha$, and pI $\kappa$ B $-\alpha$ by Western blotting. L-JWH133: JWH133 at the low dose of $5 \mathrm{mg} / \mathrm{kg}$ and H-JWH133: JWH133 at the high dose of $20 \mathrm{mg} / \mathrm{kg}$. The values presented are the mean $\pm \mathrm{SD} .{ }^{*} P<0.05$ versus PQ group; ${ }^{\#} P<0.05$ versus L-JWH133 group.

factor $\mathrm{NF}-\kappa \mathrm{B}$, which is known to be relevant to cytokine gene expression [47]. In addition, a recent study showed that silencing of JNK and p38 MAPK decreased NF- $\kappa \mathrm{B}$ phosphorylation and increased inhibitor of NF- $\kappa \mathrm{B}(\mathrm{I} \kappa \mathrm{B}) \alpha$ levels, which attenuated oxidative stress, inflammation, and apoptosis furtherly [48]. In our study, JWH133 inhibited MAPKs activity, which suggested that JWH133 may activate $\mathrm{I} \kappa \mathrm{B}-\alpha$ and attenuate the NF- $\kappa \mathrm{B}$-induced inflammatory response via inhabitation of MAPKs activity. However, this hypothesis remains to be further elucidated.

Overwhelming evidence has established an important role for endocannabinoid-CB2 receptor signaling in a large number of the major pathologies including inflammatory, autoimmune, cardiovascular, gastrointestinal, liver, kidney, neurodegenerative, psychiatric, and many other diseases [49]. CB2 receptor activation in general mediates immunosuppressive effects, which limit inflammation and associated tissue injury in large number of pathological conditions [49]. CB2 receptor agonists dramatically attenuate iNOS induction and ROS generation in LPS-activated microglia. These effects are due to their reduction of phosphorylation of ERK1/2 and activation of NF- $\kappa \mathrm{B}$ [50]. CB2 agonist inhibited LPSinduced proinflammatory cytokine expression in peripheral blood and attenuates LPS-stimulated ERK1/2 and JNK phosphorylation in monocytes [51]. JWH133 reduced expression of active p38 MAPK, JNK, and proinflammatory cytokines (IL-1 $\beta$, IL-6, and TNF- $\alpha$ ) induced cognitive improvement in a genetic mice model of Alzheimer's disease [52]. In the present study, we found that CB2 receptors were expressed in lung epithelial cells, endothelial cells, and immune cells.
The CB2 receptors expression in PQ-poisoned rats was lower than that in control rats. It may be correlated with CB2 receptor internalization. However, there may be some other reasons for this phenomenon. Therefore, the underlying mechanism needs to be further investigated in the next experiment. Our results suggest that JWH133 may exert its effect on PQ-induced lung injury and it can regulate inflammation responses including MAPKs signal pathway and NF$\kappa \mathrm{B}$ pathway via $\mathrm{CB} 2$ receptor activation. This hypothesis requires further verification in vitro.

\section{Conclusions}

In summary, we obtained the results that PQ administration reduced the $\mathrm{PaO}_{2}$ in the arterial blood, recruited leukocytes with the enhanced expression of cytokines (TNF- $\alpha$ and IL$1 \beta)$, activated the MAPKs signaling including p38MAPK, $\mathrm{ERK} 1 / 2$, JNK1/2, and the nuclear transcription factor NF$\kappa \mathrm{B}$, and finally evoked inflammatory response with manifestation of alveolar structure damage, congestion, and edema in the lung tissue. These effects were attenuated by CB2 agonist JWH133. Moreover, NF- $\kappa \mathrm{B}$ activation was significantly suppressed and the phosphorylation of p38MAPK, ERK1/2, and JNK1/2 was substantially downregulated after JWH133 pretreatment. Taken together, the results suggest that activating CB2 receptor can inhibit the proinflammatory cytokine expression and may exert a protective effect on PQinduced ALI, and it potentially contributes to the suppression of the activation of MAPKs and NF- $\kappa$ B pathways. The specific biological mechanisms of MAPKs and NF- $\kappa$ B pathways 
triggered by $\mathrm{CB} 2$ activation need to be further investigated in the next experiments using CB2-selective antagonists or knockout animals. These current results may only have important implications for the alleviation of acute lung injury caused by PQ.

$\begin{array}{ll}\text { Abbreviations } \\ \text { PQ: } & \text { Paraquat } \\ \mathrm{CB} 2: & \text { Cannabinoid receptor- } 2 \\ \text { BALF: } & \text { Bronchoalveolar lavage fluid } \\ \text { TNF- } \alpha: & \text { Tumor necrosis factor- } \alpha \\ \mathrm{IL}-1 \beta: & \text { Interleukin-1 } \beta \\ \mathrm{W} / \mathrm{D}: & \text { Wet-to-dry weight } \\ \mathrm{MPO}: & \text { Myeloperoxidase } \\ \mathrm{ERK} 1 / 2: & \text { Extracellular signal-regulated kinase } 1 / 2 \\ \text { p38MAPK: } & \text { p38 Mitogen-activated protein kinase } \\ \mathrm{JNK}: & \text { c-Jun N-terminal kinase } \\ \mathrm{NF}-\kappa \mathrm{B}: & \text { Nuclear factor- } \kappa \mathrm{B} \\ \mathrm{I} \kappa \mathrm{B}-\alpha: & \text { Inhibitor of } \kappa \mathrm{B} \text { protein- } \alpha \\ \mathrm{ROS}: & \text { Reactive oxygen species } \\ \mathrm{ALI}: & \text { Acute lung injury } \\ \mathrm{ARDS}: & \text { Acute respiratory distress syndrome } \\ \mathrm{PaO}{ }_{2}: & \text { Arterial oxygen partial pressure. }\end{array}$

\section{Conflict of Interests}

The authors declare that they have no conflict of interests.

\section{Acknowledgments}

This work is support by the National Natural Science Foundation of China (Grant no. 81171793/H1503) and the Science Technology Plan of Liaoning Province (Grant no. 2011225038).

\section{References}

[1] R. J. Dinis-Oliveira, J. A. Duarte, A. Sánchez-Navarro, F. Remião, M. L. Bastos, and F. Carvalho, "Paraquat poisonings: mechanisms of lung toxicity, clinical features, and treatment," Critical Reviews in Toxicology, vol. 38, no. 1, pp. 13-71, 2008.

[2] N. Venkatesan, "Pulmonary protective effects of curcumin against paraquat toxicity," Life Sciences, vol. 66, no. 2, pp. L-21L-28, 1999.

[3] S. Kishimoto, M. Muramatsu, M. Gokoh, S. Oka, K. Waku, and T. Sugiura, "Endogenous cannabinoid receptor ligand induces the migration of human natural killer cells," Journal of Biochemistry, vol. 137, no. 2, pp. 217-223, 2005.

[4] S. Oka, S. Ikeda, S. Kishimoto et al., "2-Arachidonoylglycerol, an endogenous cannabinoid receptor ligand, induces the migration of EoL-1 human eosinophilic leukemia cells and human peripheral blood eosinophils," Journal of Leukocyte Biology, vol. 76, no. 5, pp. 1002-1009, 2004.

[5] K. Mackie, "Cannabinoid receptors as therapeutic targets," Annual Review of Pharmacology and Toxicology, vol. 46, pp. 101122, 2006.

[6] N. E. Buckley, "The peripheral cannabinoid receptor knockout mice: an update," The British Journal of Pharmacology, vol. 153, no. 2, pp. 309-318, 2008.
[7] S. Bátkai, D. Osei-Hyiaman, H. Pan et al., "Cannabinoid-2 receptor mediates protection against hepatic ischemia/reperfusion injury," The FASEB Journal, vol. 21, no. 8, pp. 1788-1800, 2007.

[8] M. Rajesh, P. Mukhopadhyay, S. Bátkai et al., "CB2-receptor stimulation attenuates TNF- $\alpha$-induced human endothelial cell activation, transendothelial migration of monocytes, and monocyte-endothelial adhesion," The American Journal of Physiology-Heart and Circulatory Physiology, vol. 293, no. 4, pp. H2210-H2218, 2007.

[9] F. Montecucco, S. Lenglet, V. Braunersreuther et al., " $\mathrm{CB} 2$ cannabinoid receptor activation is cardioprotective in a mouse model of ischemia/reperfusion," Journal of Molecular and Cellular Cardiology, vol. 46, no. 5, pp. 612-620, 2009.

[10] S. Bátkai, M. Rajesh, P. Mukhopadhyay et al., "Decreased agerelated cardiac dysfunction, myocardial nitrative stress, inflammatory gene expression, and apoptosis in mice lacking fatty acid amide hydrolase," The American Journal of Physiology-Heart and Circulatory Physiology, vol. 293, no. 2, pp. H909-H918, 2007.

[11] P. Pacher, S. Bátkai, and G. Kunos, "The endocannabinoid system as an emerging target of pharmacotherapy," Pharmacological Reviews, vol. 58, no. 3, pp. 389-462, 2006.

[12] P. Pacher and G. Haskó, "Endocannabinoids and cannabinoid receptors in ischaemia-reperfusion injury and preconditioning," The British Journal of Pharmacology, vol. 153, no. 2, pp. 252$262,2008$.

[13] R. G. Pertwee, "Emerging strategies for exploiting cannabinoid receptor agonists as medicines," The British Journal of Pharmacology, vol. 156, no. 3, pp. 397-411, 2009.

[14] P. Mukhopadhyay, M. Rajesh, B. Horváth et al., "Cannabidiol protects against hepatic ischemia/reperfusion injury by attenuating inflammatory signaling and response, oxidative/nitrative stress, and cell death," Free Radical Biology and Medicine, vol. 50, no. 10, pp. 1368-1381, 2011.

[15] Z. N. Liu, M. Zhao, Q. Zheng, H. Y. Zhao, W. J. Hou, and S. L. Bai, "Inhibitory effects of rosiglitazone on paraquat-induced acute lung injury in rats," Acta Pharmacologica Sinica, vol. 34, no. 10, pp. 1317-1324, 2013.

[16] H. Yin, X. B. Jin, Q. Gong et al., "Fructose-1,6-diphosphate attenuates acute lung injury induced by lipopolysaccharide in mice," International Immunopharmacology, vol. 8, no. 13-14, pp. 1842-1847, 2008.

[17] D. M. Guidot, H. G. Folkesson, L. Jain, J. I. Sznajder, J. Pittet, and M. A. Matthay, "Integrating acute lung injury and regulation of alveolar fluid clearance," The American Journal of PhysiologyLung Cellular and Molecular Physiology, vol. 291, no. 3, pp. L301L306, 2006.

[18] S. E. Orfanos, I. Mavrommati, I. Korovesi, and C. Roussos, "Pulmonary endothelium in acute lung injury: from basic science to the critically ill," Intensive Care Medicine, vol. 30, no. 9, pp. 1702-1714, 2004.

[19] M. Rojas, C. R. Woods, A. L. Mora, J. Xu, and K. L. Brigham, "Endotoxin-induced lung injury in mice: structural, functional, and biochemical responses," The American Journal of Physiology_Lung Cellular and Molecular Physiology, vol. 288, no. 2, pp. L333-L341, 2005.

[20] R. K. Albert, D. Leasa, M. Sanderson, H. T. Robertson, and M. P. Hlastala, "The prone position improves arterial oxygenation and reduces shunt in oleic-acid-induced acute lung injury," The American Review of Respiratory Disease, vol. 135, no. 3, pp. 628633, 1987. 
[21] M. Cepkova and M. A. Matthay, "Pharmacotherapy of acute lung injury and the acute respiratory distress syndrome," Journal of Intensive Care Medicine, vol. 21, no. 3, pp. 119-143, 2006.

[22] S. J. Klebanoff, "Myeloperoxidase: friend and foe," Journal of Leukocyte Biology, vol. 77, no. 5, pp. 598-625, 2005.

[23] R. F. Guo, A. B. Lentsch, R. L. Warner et al., "Regulatory effects of eotaxin on acute lung inflammatory injury," Journal of Immunology, vol. 166, no. 8, pp. 5208-5218, 2001.

[24] Y. Ishida, T. Takayasu, A. Kimura et al., "Gene expression of cytokines and growth factors in the lungs after paraquat administration in mice," Legal Medicine, vol. 8, no. 2, pp. 102109, 2006.

[25] K. Amirshahrokhi and S. Bohlooli, "Effect of methylsulfonylmethane on paraquat-induced acute lung and liver injury in mice," Inflammation, vol. 36, no. 5, pp. 1111-1121, 2013.

[26] H. Q. Zhang, H. D. Wang, D. X. Lu et al., "Berberine inhibits cytosolic phospholipase A2 and protects against LPS-induced lung injury and lethality independent of the $\alpha 2$-adrenergic receptor in mice," Shock, vol. 29, no. 5, pp. 617-622, 2008.

[27] J. H. Roux, H. Kawakatsu, B. Gartland et al., "Interleukin-1 $\beta$ decreases expression of the epithelial sodium channel $\alpha$-subunit in alveolar epithelial cells via a p38 MAPK-dependent signaling pathway," The Journal of Biological Chemistry, vol. 280, no. 19, pp. 18579-18589, 2005.

[28] B. M. Hybertson, Y. M. Lee, H. G. Cho, O. J. Cho, and J. E. Repine, "Alveolar type II cell abnormalities and peroxide formation in lungs of rats given IL-1 intratracheally," Inflammation, vol. 24, no. 4, pp. 289-303, 2000.

[29] Y. M. Lee, B. M. Hybertson, H. G. Cho et al., "Platelet-activating factor contributes to acute lung leak in rats given interleukin1 intratracheally," The American Journal of Physiology-Lung Cellular and Molecular Physiology, vol. 279, no. 1, pp. L75-L80, 2000.

[30] A. B. Lentsch and P. A. Ward, "Activation and regulation of NF $\kappa \mathrm{B}$ during acute inflammation," Clinical Chemistry and Laboratory Medicine, vol. 37, no. 3, pp. 205-208, 1999.

[31] J. Hawiger, "Innate immunity and inflammation: a transcriptional paradigm," Immunologic Research, vol. 23, no. 2-3, pp. 99109, 2001.

[32] T. Huxford and G. Ghosh, "A structural guide to proteins of the NF- $\kappa \mathrm{B}$ signaling module," Cold Spring Harbor Perspectives in Biology, vol. 1, no. 3, Article ID a000075, 2009.

[33] P. A. Baeuerle and V. R. Baichwal, "NF- $\kappa$ B as a frequent target for immunosuppressive and anti-inflammatory molecules," Advances in Immunology, vol. 65, pp. 111-137, 1997.

[34] P. P. Tak and G. S. Firestein, "NF- $\kappa$ B: a key role in inflammatory diseases," Journal of Clinical Investigation, vol. 107, no. 1, pp. 7-11, 2001.

[35] M. Guha and N. Mackman, "LPS induction of gene expression in human monocytes," Cellular Signalling, vol. 13, no. 2, pp. 8594, 2001.

[36] A. K. Lee, S. H. Sung, Y. C. Kim, and S. G. Kim, "Inhibition of lipopolysaccharide-inducible nitric oxide synthase, TNF- $\alpha$ and COX-2 expression by sauchinone effects on I- $\kappa \mathrm{B} \alpha$ phosphorylation, C/EBP and AP-1 activation," The British Journal of Pharmacology, vol. 139, no. 1, pp. 11-20, 2003.

[37] J. J. Baldassare, Y. Bi, and C. J. Bellone, "The role of p38 mitogenactivated protein kinase in IL-1 $\beta$ transcription," Journal of Immunology, vol. 162, no. 9, pp. 5367-5373, 1999.

[38] E. Hitti, T. Iakovleva, M. Brook et al., "Mitogen-activated protein kinase-activated protein kinase 2 regulates tumor necrosis factor mRNA stability and translation mainly by altering tristetraprolin expression, stability, and binding to adenine/uridinerich element," Molecular and Cellular Biology, vol. 26, no. 6, pp. 2399-2407, 2006.

[39] C. Patil, X. Zhu, C. Rossa Jr., Y. J. Kim, and K. L. Kirkwood, "p38 MAPK regulates IL-1 $\beta$ induced IL-6 expression through mRNA stability in osteoblasts," Immunological Investigations, vol. 33, no. 2, pp. 213-233, 2004.

[40] Z. Han, D. L. Boyle, L. Chang et al., "c-Jun N-terminal kinase is required for metalloproteinase expression and joint destruction in inflammatory arthritis," Journal of Clinical Investigation, vol. 108, no. 1, pp. 73-81, 2001.

[41] W. H. Park, "The effect of MAPK inhibitors and ROS modulators on cell growth and death of $\mathrm{H}_{2} \mathrm{O}_{2}$-treated HeLa cells," Molecular Medicine Reports, vol. 8, no. 2, pp. 557-564, 2013.

[42] S. Zeng, N. Feirt, M. Goldstein et al., "Blockade of receptor for advanced glycation end product (RAGE) attenuates ischemia and reperfusion injury to the liver in mice," Hepatology, vol. 39, no. 2, pp. 422-432, 2004.

[43] I. N. Hines and M. B. Grisham, "Divergent roles of superoxide and nitric oxide in liver ischemia and reperfusion injury," Journal of Clinical Biochemistry and Nutrition, vol. 48, no. 1, pp. 50-56, 2011.

[44] Y. Abe, I. N. Hines, G. Zibari et al., "Mouse model of liver ischemia and reperfusion injury: method for studying reactive oxygen and nitrogen metabolites in vivo," Free Radical Biology and Medicine, vol. 46, no. 1, pp. 1-7, 2009.

[45] T. Cindrova-Davies, "Gabor Than award lecture 2008: preeclampsia-from placental oxidative stress to maternal endothelial dysfunction," Placenta, vol. 30, supplement, pp. S55-S65, 2009.

[46] G. Pearson, F. Robinson, T. B. Gibson et al., "Mitogen-activated protein (MAP) kinase pathways: regulation and physiological functions," Endocrine Reviews, vol. 22, no. 2, pp. 153-183, 2001.

[47] J. C. Lee, J. T. Laydon, P. C. McDonnell et al., "A protein kinase involved in the regulation of inflammatory cytokine biosynthesis," Nature, vol. 372, no. 6508, pp. 739-746, 1994.

[48] J. Tan, D. Liu, X. Lv et al., "MAPK mediates inflammatory response and cell death in rat pulmonary microvascular endothelial cells in an ischemia-reperfusion model of lung transplantation," Journal of Heart and Lung Transplantation, vol. 32, no. 8, pp. 823-831, 2013.

[49] P. Pacher and R. Mechoulam, "Is lipid signaling through cannabinoid 2 receptors part of a protective system?” Progress in Lipid Research, vol. 50, no. 2, pp. 193-211, 2011.

[50] R. Ribeiro, J. Wen, S. Li, and Y. Zhang, "Involvement of ERK1/2, cPLA2 and NF- $\kappa$ B in microglia suppression by cannabinoid receptor agonists and antagonists," Prostaglandins and Other Lipid Mediators, vol. 100-101, no. 1, pp. 1-14, 2013.

[51] J. Gertsch, M. Leonti, S. Raduner et al., "Beta-caryophyllene is a dietary cannabinoid," Proceedings of the National Academy of Sciences of the United States of America, vol. 105, no. 26, pp. 9099-9104, 2008.

[52] E. Aso, S. Juvés, R. Maldonado, and I. Ferrer, "CB2 cannabinoid receptor agonist ameliorates alzheimer-like phenotype in A $\beta$ PP/PS1 mice," Journal of Alzheimer's Disease, vol. 35, no. 4, pp. 847-858, 2013. 


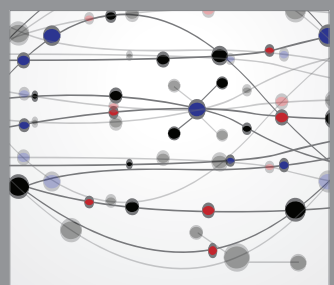

The Scientific World Journal
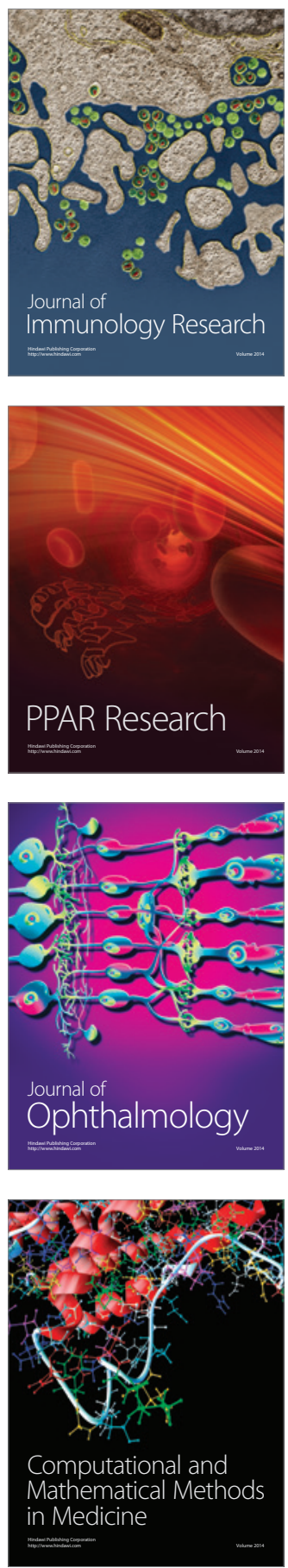

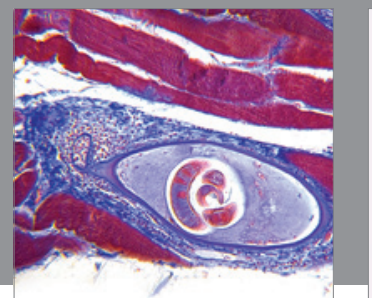

Gastroenterology

Research and Practice
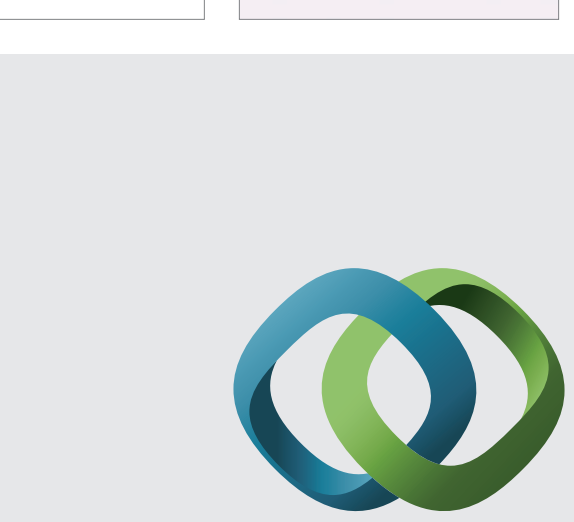

\section{Hindawi}

Submit your manuscripts at

http://www.hindawi.com
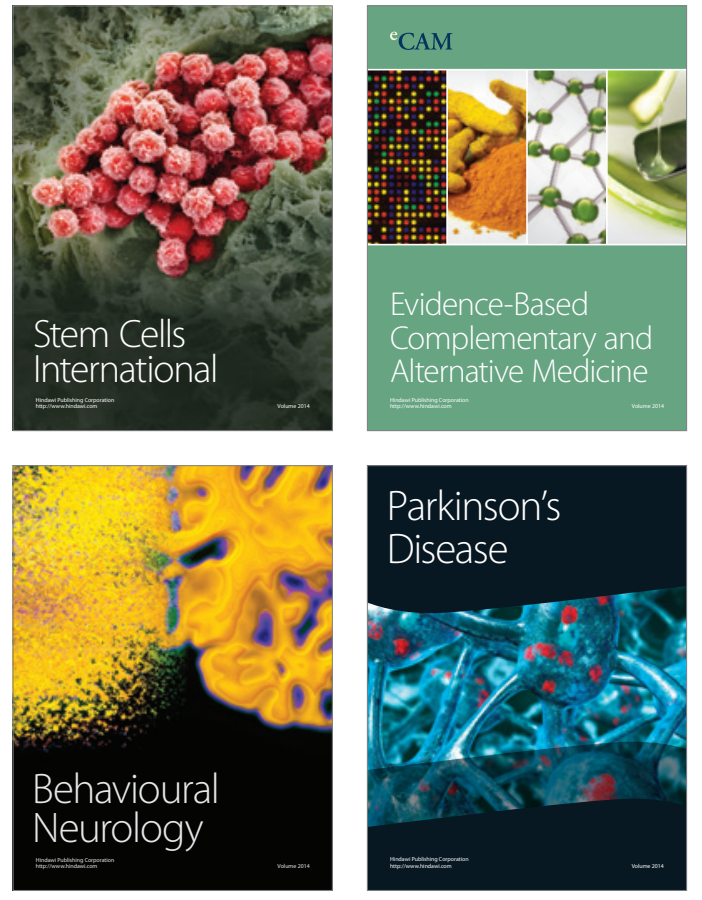
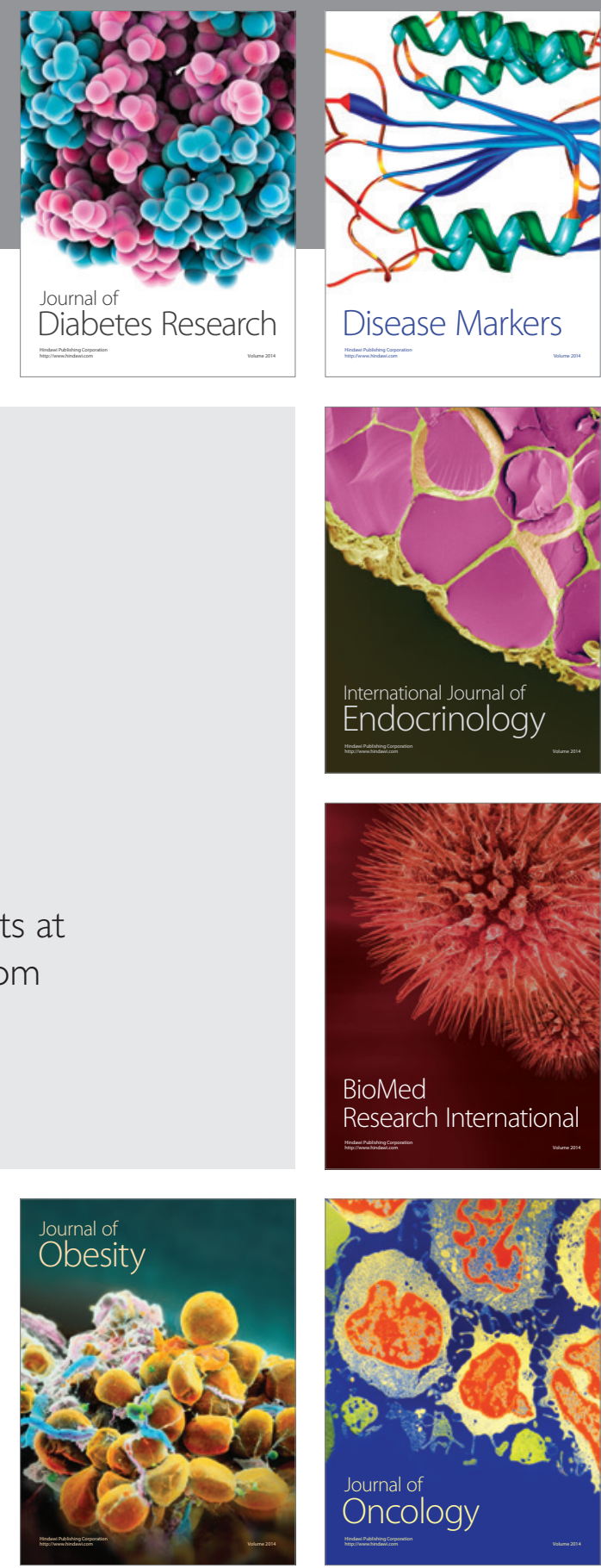

Disease Markers
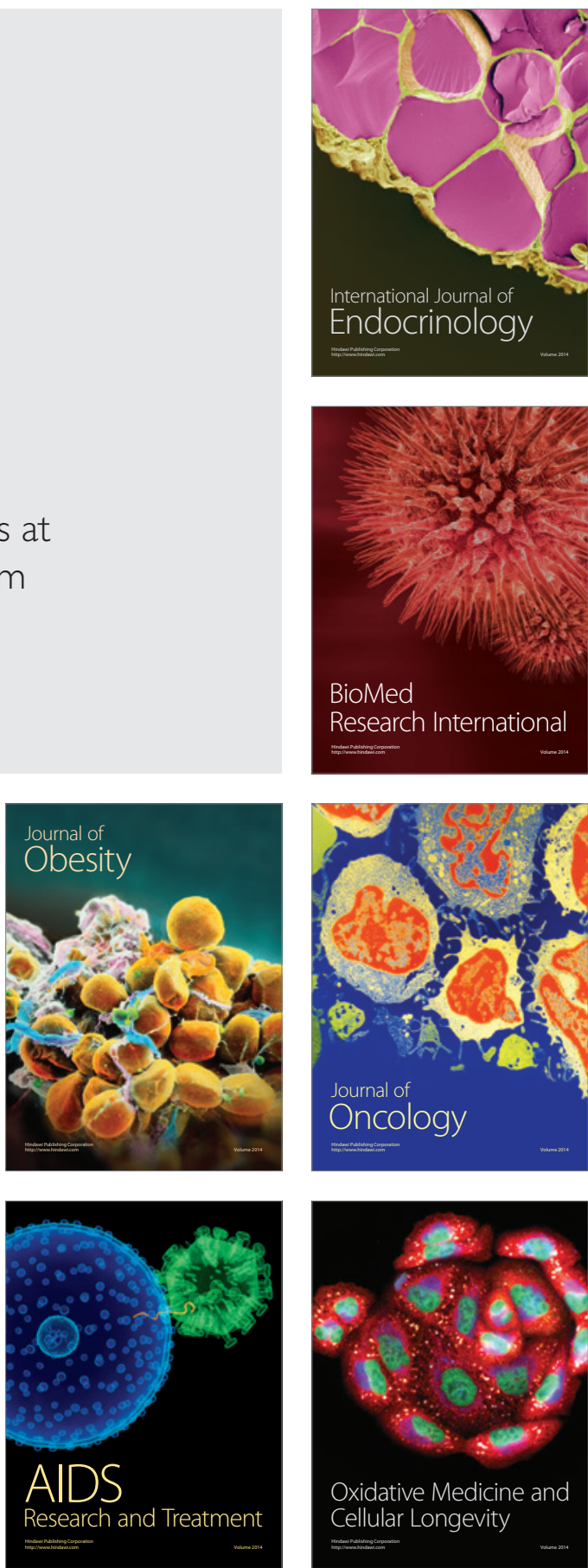